\title{
Comparing Methods Used by the U.S. Geological Survey Coastal and Marine Geology Program for Deriving Shoreline Position from Lidar Data
}

Open-File Report 2018-1121 



\section{Comparing Methods Used by the U.S. Geological Survey Coastal and Marine Geology Program for Deriving Shoreline Position from Lidar Data}

By Amy S. Farris, Kathryn M. Weber, Kara S. Doran, and Jeffrey H. List

Open-File Report 2018-1121 


\title{
U.S. Department of the Interior \\ RYAN K. ZINKE, Secretary
}

\author{
U.S. Geological Survey \\ James F. Reilly II, Director
}

U.S. Geological Survey, Reston, Virginia: 2018

For more information on the USGS - the Federal source for science about the Earth, its natural and living resources, natural hazards, and the environment-visit https://www.usgs.gov or call 1-888-ASK-USGS.

For an overview of USGS information products, including maps, imagery, and publications,

visit https://store.usgs.gov.

Any use of trade, firm, or product names is for descriptive purposes only and does not imply endorsement by the U.S. Government.

Although this information product, for the most part, is in the public domain, it also may contain copyrighted materials as noted in the text. Permission to reproduce copyrighted items must be secured from the copyright owner.

Suggested citation:

Farris, A.S., Weber, K.M., Doran, K.S., and List, J.H., 2018, Comparing methods used by the U.S. Geological Survey Coastal and Marine Geology Program for deriving shoreline position from lidar data: U.S. Geological Survey Open-File Report 2018-1121, 13 p., https://doi.org/10.3133/ofr20181121.

ISSN 2331-1258 (online) 


\section{Contents}

Abstract

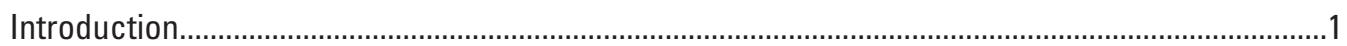

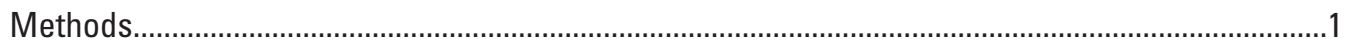

Shoreline Extraction Methods ..............................................................................................

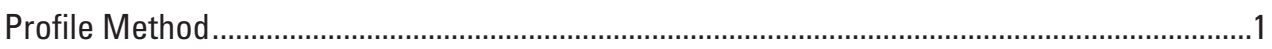

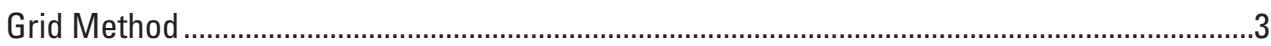

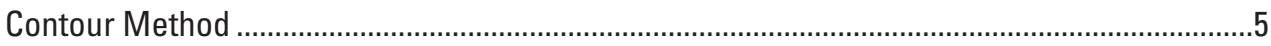

Smoothed Contour Method .....................................................................................................

Smoothed Contour/Manual Hybrid Method ...............................................................................

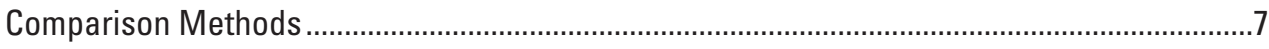

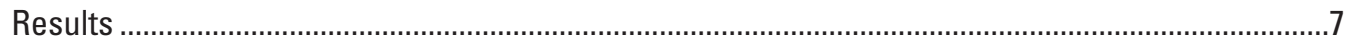

Comparison of Shoreline Position Interpolated to 50-Meter Transects

(September 30, 2000, Lidar Survey) .............................................................................

Evaluation of Uncertainty for Grid and Profile Methods at Originally Derived

20-Meter Transect Spacing (September 30, 2000, Survey) ...........................................9

Discussion.........................................................................................................................

Comparison of Shoreline Position Interpolated to 50-Meter Transects

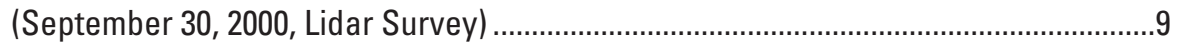

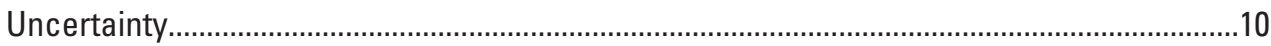

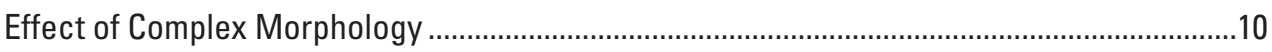

Additional Qualitative Factors .........................................................................................11

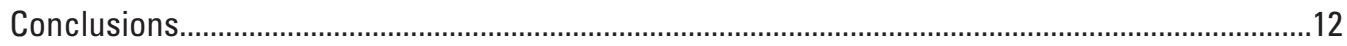

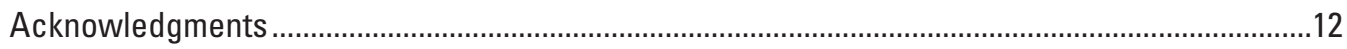

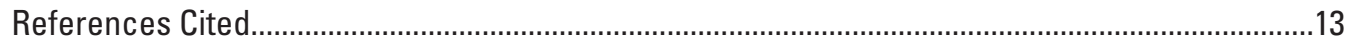

\section{Figures}

1. Screenshot showing an example of the graphical user interface used to check the solutions .................................................................................................................

2. Screenshot showing an example of a solution the user might want to delete ..................4

3. Screenshot showing an example of an extrapolated solution ............................................5

4. The rotated interpolated elevation grid color-coded by height, and the probability that each grid cell is equal to mean high water ...............................................................6

5. Graph showing an example of the spatial variability of differences between shoreline methods .......................................................................................................

6. Graph showing the spatial variability of differences between Grid shoreline and Profile shoreline when they are still at their originally derived locations.........................9

7. Graph showing profile method uncertainty terms versus Profile method foreshore

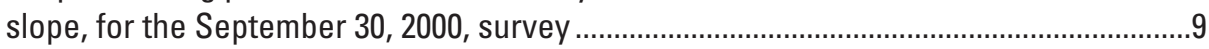

8. Graph showing grid method uncertainty terms versus Grid method foreshore slope, for the September 30, 2000, survey ...................................................................10

9. Graph showing map view comparison of variations of the Contour shoreline method using the September 30, 2000, lidar survey.

10. Graph showing a comparison between Grid, Profile, and Smoothed Contour/ Manual hybrid methods for deriving shorelines using data collected on November 5, 2012. 


\section{Tables}

1. Methods for extracting shoreline position from light detection and ranging (lidar) data compared in this report.

2. Mean differences in shoreline positions (in meters) ........................................................8

3. Root mean square (RMS) differences in shoreline positions (in meters) ...........................8

4. Root mean square (RMS) differences in shoreline positions after the mean difference is removed

5. Comparison of methods

\section{Conversion Factors}

International System of Units to U.S. customary units

\begin{tabular}{lll}
\hline \multicolumn{1}{c}{ Multiply } & By & To obtain \\
\hline centimeter $(\mathrm{cm})$ & 0.3937 & inch (in.) \\
meter $(\mathrm{m})$ & 1.094 & yard (yd) \\
kilometer $(\mathrm{km})$ & 0.6214 & mile (mi) \\
\hline
\end{tabular}

Temperature in degrees Celsius $\left({ }^{\circ} \mathrm{C}\right)$ may be converted to degrees Fahrenheit $\left({ }^{\circ} \mathrm{F}\right)$ as ${ }^{\circ} \mathrm{F}=\left(1.8 \times{ }^{\circ} \mathrm{C}\right)+32$.

Temperature in degrees Fahrenheit $\left({ }^{\circ} \mathrm{F}\right)$ may be converted to degrees Celsius $\left({ }^{\circ} \mathrm{C}\right)$ as ${ }^{\circ} \mathrm{C}=\left({ }^{\circ} \mathrm{F}-32\right) / 1.8$.

\section{Datum}

Vertical coordinate information is referenced to the North American Vertical Datum of 1988 (NAVD 88).

Horizontal coordinate information is referenced to the North American Datum of 1983 (NAD 83). Elevation, as used in this report, refers to distance above the vertical datum.

\section{Abbreviations}

$\mathrm{Cl}$

GUI

lidar

MHW

NOAA

$\mathrm{QA} / \mathrm{QC}$

RMS

USGS

UTM confidence interval

graphical user interface

light detection and ranging

mean high water

National Oceanic and Atmospheric Administration

quality assurance/quality control

root mean square

U.S. Geological Survey

Universal Transverse Mercator 


\title{
Comparing Methods Used by the U.S. Geological Survey Coastal and Marine Geology Program for Deriving Shoreline Position from Lidar Data
}

\author{
By Amy S. Farris, Kathryn M. Weber, Kara S. Doran, and Jeffrey H. List
}

\begin{abstract}
The U.S. Geological Survey Coastal and Marine Geology Program uses three methods to derive a datum-based, mean high water shoreline on open-ocean coasts from light detection and ranging (lidar) elevation surveys. This work compared the shorelines produced by the three methods for two different surveys: one survey with simple beach morphology, and one survey with complex beach morphology. For the survey with simple beach morphology, the three methods gave very similar results. The mean differences were less than 0.1 meter, and the root mean square differences were all less than 1.0 meter. For the survey of a beach with complex morphology, the quality control used in the Profile method and Smoothed Contour/ Manual Hybrid method produced cleaner shorelines than the Grid method. Only the Profile method can extrapolate if there is no data around mean high water. The Grid and Profile methods produce a point by point estimate of uncertainty which is needed for some applications. Only the Contour method can be easily transferred to external users.
\end{abstract}

\section{Introduction}

The U.S. Geological Survey (USGS) Coastal and Marine Geology Program uses three different methods to derive a datum-based, mean high water (MHW) shoreline on open-ocean coasts from light detection and ranging (lidar) elevation surveys. This work compared the three methods to verify that they all give similar results. This work also compared the strengths and weaknesses of each method. To compare the methods, we used two lidar datasets from Fire Island, New York: data from a survey by the National Oceanic and Atmospheric Administration (NOAA), the National Aeronautics and Space Administration, and the USGS, using the ATM-II system, collected on September 30, 2000 (NOAA, 2000); and data from a post-Hurricane Sandy survey collected by a contractor on November 5, 2012 (USGS, 2012). The elevation of MHW was derived from NOAA tidal datum sheets by Weber and others (2005) and is 0.46 meters (m) above the North American Vertical Datum of 1988 (NAVD 88) for Fire Island. As we do not know the true shoreline position, our evaluation consisted of a comparison between methods.

\section{Methods}

\section{Shoreline Extraction Methods}

We compared three principal methods for extracting shoreline position from lidar data, which we called Grid, Profile, and Contour (table 1). In the process of our evaluation, two of the methods, Profile and Contour, were subdivided, giving a total of seven methods compared (table 1). Table 1 provides definitions for each methodology. The Grid and Profile methods are written in the programming language MATLAB ${ }^{\circledR}$. Both methods require the user to first define a coast-following reference line. For this study, both methods use the same reference line with profiles (or transects) spaced $20 \mathrm{~m}$ apart. The Contour method is executed in $\operatorname{ArcGIS}^{\circledR}$ software by Esri. It does not require a baseline. All methods use data in the Universal Transverse Mercator (UTM) coordinate system.

\section{Profile Method}

As mentioned above, the Profile method uses a coastfollowing reference line with equally spaced profiles. All lidar data points that are within $1 \mathrm{~m}$ of each profile are associated with that profile. All further work is done on these 2-m wide profiles, working on one profile at a time.

The Profile method fits a linear regression through data points located on the foreshore, and thus the method must determine which data points should be used in the regression. The process of determining these data points begins by removing outliers. Next, the "starting point" is found. The starting point is the cross-shore location where the search for the shoreline begins. Finding the starting point is done in an automated procedure in which water points are identified and 
Table 1. Methods for extracting shoreline position from light detection and ranging (lidar) data compared in this report.

[Alongshore data spacing refers to the shorelines derived from the September 30, 2000, lidar survey. m, meter; MHW, mean high water]

\begin{tabular}{|c|c|}
\hline Name of method & Description \\
\hline Profile20 & $\begin{array}{l}\text { Profile method, basic method described by Stockdon and others (2002), but heavily modified. Uses a } \\
20 \text {-m cross-shore maximum window width in the foreshore data search. Derived at a } 20 \text {-m along- } \\
\text { shore spacing. Provides a point-by-point estimate of shoreline position uncertainty. }\end{array}$ \\
\hline Profile10 & $\begin{array}{l}\text { Profile method, basic method described by Stockdon and others (2002), but heavily modified. Uses a } \\
10 \text {-m cross-shore maximum window width in the foreshore data search. Derived at a } 20 \text {-m along- } \\
\text { shore spacing. Provides a point-by-point estimate of shoreline position uncertainty. }\end{array}$ \\
\hline Contour & $\begin{array}{l}\text { Output of MHW contour from ArcTools }>>3 \text { D Analyst }>>\text { Raster Surface }>>\text { Contour, uses a large } \\
\text { contour interval }(50 \mathrm{~m} \text { ) with base contour set at } 0.46 \mathrm{~m} \text {. Alongshore spacing variable, but averages } \\
0.3 \mathrm{~m} \text {. Provides a bulk estimate of shoreline position uncertainty. }\end{array}$ \\
\hline Smoothed Contour Bend Simplify & $\begin{array}{l}\text { Contour shoreline smoothed using ArcTools }>>\text { Data Management Tools }>>\text { Generalization }>> \\
\text { Simplify Line, algorithm Bend Simplify with } 10 \text {-m reference baseline. Alongshore spacing variable, } \\
\text { but averages } 6.0 \mathrm{~m} \text {. Provides a bulk estimate of shoreline position uncertainty. }\end{array}$ \\
\hline Smoothed Contour/Manual Hybrid & $\begin{array}{l}\text { Contour shoreline manual edited using lidar data as a guide. It is then smoothed using ArcTools }>> \\
\text { Data Management Tools }->\text { Generalization }->\text { Smooth Line, with PAEK algorithm set to } 10 \mathrm{~m} \text {. } \\
\text { Alongshore spacing variable, but averages } 1.3 \text { m. Provides a bulk estimate of shoreline position } \\
\text { uncertainty. }\end{array}$ \\
\hline
\end{tabular}

the elevation of the water relative to $\mathrm{MHW}$ is determined to exclude water points from the linear regression. There are several free parameters that can be adjusted by the user to improve the results.

After the starting point is located, the next step is to determine the best window of data in which to fit the regression. Ideally, all data points in the window should be on the foreshore, near MHW. The methodology begins at the starting point and searches for a window of data that meets four criteria: (1) the window of data must contain at least 10 points, (2) the mean elevation of the points in the window must fall within a certain range, (3) the linear regression fit through the points must have an r-squared value greater than 0.75 , and (4) the linear regression through the points must slope down towards the ocean. The first three criteria can be adjusted by the user to improve the quantity and quality of shoreline solutions in the dataset.

Once the best window of data is identified, a linear regression is fit through the points in the window. The shoreline position is determined by evaluating the regression at MHW. The slope of the regression is an estimate of the slope of the foreshore. The 95-percent confidence interval (CI) on the regression is calculated.

The MATLAB ${ }^{\circledR}$ code includes a graphical user interface (GUI) so that the user can view the solution for each profile. All the data points on the profile are plotted, and the points used in the regression are highlighted. The regression line, shoreline location, and error bars are also plotted (fig. 1). The GUI allows the user to run the code and view the results profile by profile. Parameters can be adjusted to improve the shoreline solutions and (or) increase the number of solutions in the dataset. If the lidar data are dense and the beach morphology is simple, the default parameters usually produce excellent results (that is, there is a solution for nearly every profile and each solution falls at the intersection of MHW with the data, as it does in fig. 1). However, if the data points are sparse or the morphology is complex, the default parameters can yield few or poor solutions. Changing the many free parameters allows the user to achieve good solutions in a wide variety of situations.

The GUI also allows the user to reject individual solutions as needed. For example, a merging swash bar might cause the code to put the shoreline on the wrong foreshore (fig. 2). This topic is discussed further in the section "Effect of Complex Morphology." If MHW is not within the window of data, the shoreline point may be determined by assuming a constant foreshore slope and extrapolating the linear regression to the MHW elevation (fig. 3). As a final check, the shoreline solutions are plotted in map view on the lidar point cloud data. If any points seem to be wrong (for example, on the wrong foreshore), they can be deleted. 


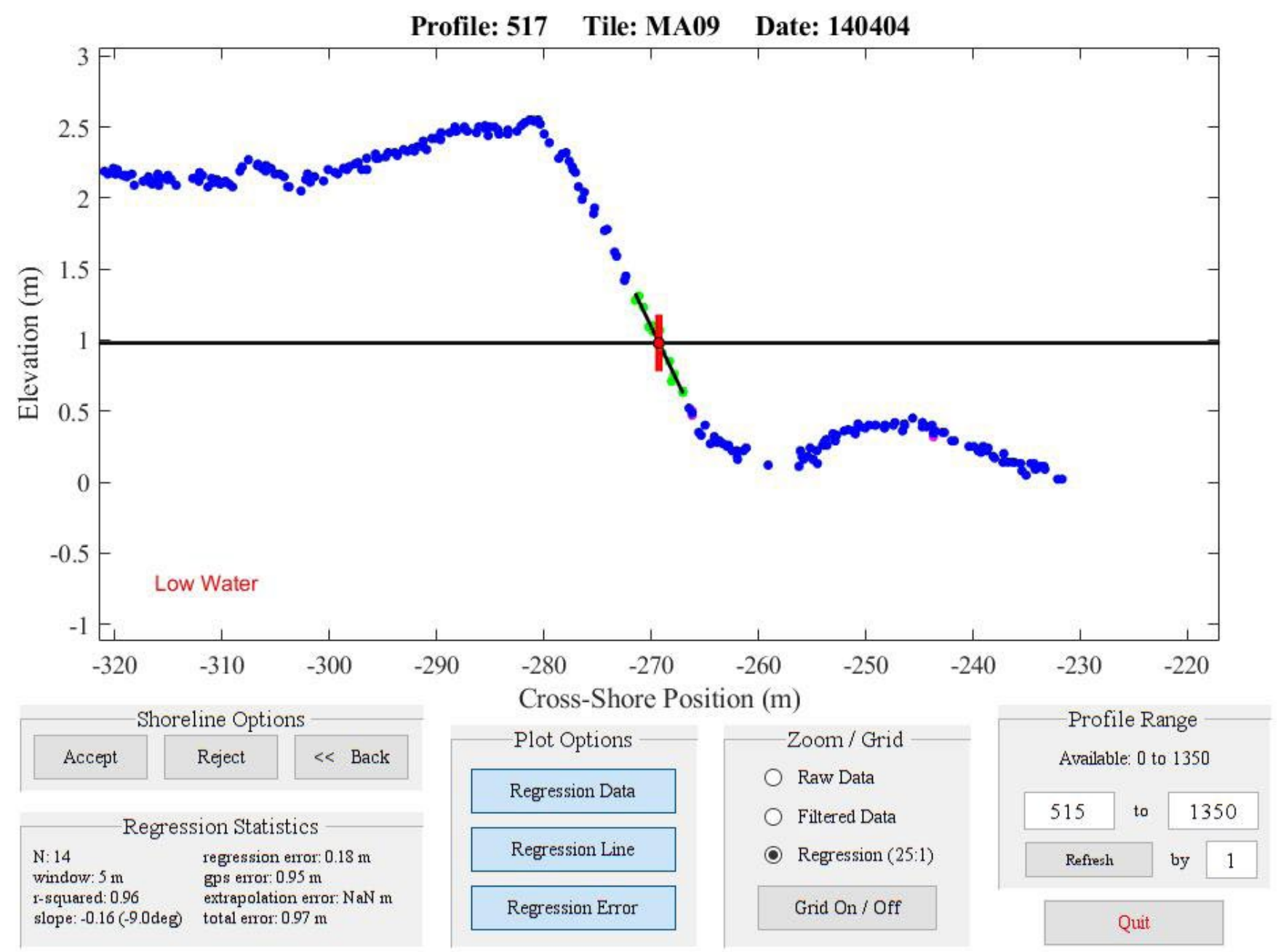

Figure 1. An example of the graphical user interface used to check the solutions. Blue points show cross-shore profile data. Green points are profile data used in the linear regression, with the slope of that linear regression shown by the thin black line through those points. The horizontal black line is the height of mean high water (MHW) in meters $(\mathrm{m})$ relative to the North American Vertical Datum (NAVD 88). The red point is the calculated shoreline position, and the red lines of either side of this point show the 95-percent confidence interval $(\mathrm{Cl})$ of the regression.

The Profile method estimates the uncertainty of each shoreline solution by considering three sources of uncertainty. The first is the uncertainty due to the linear regression. This is simply calculated as the 95-percent $\mathrm{CI}$ associated with the regression estimate. The second estimate of uncertainty is associated with the system of lidar data collection. It has been historically shown that lidar data can drift vertically by \pm 15 centimeters $(\mathrm{cm})$ (Sallenger and others, 2003). (Lidar data collected by newer sensors may not drift in the same way, but points will still have a vertical root mean square [RMS] error that may be of a similar magnitude.) The $15-\mathrm{cm}$ vertical drift uncertainty is converted into a horizontal uncertainty by using the beach slope. The final potential source of uncertainty in the shoreline position is due to extrapolation, if any was done. When calculating a shoreline point using extrapolation, it is assumed that the foreshore beach slope is constant. Since this may not be the case, the code calculates the amount of uncertainty in the horizontal shoreline position due to the likely variability of the beach slope between the last point on the linear regression and the MHW elevation. The total error on the shoreline point is calculated by adding the three error terms in quadrature.

\section{Grid Method}

The Grid shoreline method makes use of elevation data that are scale-controlled, interpolated, and gridded. Threedimensional lidar data are rotated according to the shoreline angle and then gridded by using a fixed-scale interpolator (Plant and others, 2002). This allows for variability in crossshore and alongshore resolution; typically, the cross-shore 
Profile: 4876 Tile: NY04 Date: 000930

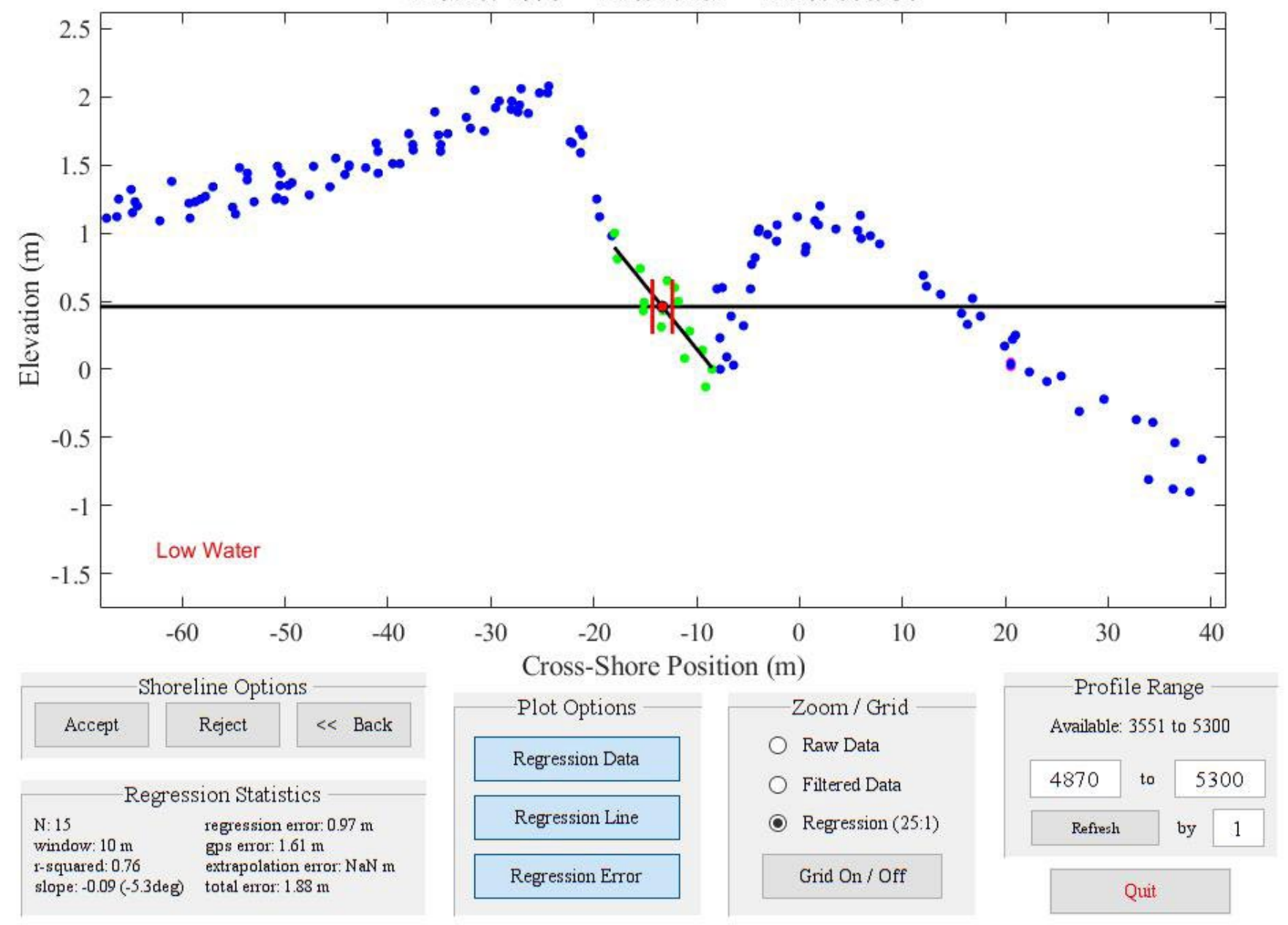

Figure 2. An example of a solution the user might want to delete. Blue points show cross-shore profile data. Green points are profile data used in the linear regression, with the slope of that linear regression shown by the thin black line through those points. The horizontal black line is the height of mean high water $(\mathrm{MHW})$ in meters $(\mathrm{m})$ relative to the North American Vertical Datum of 1988 (NAVD 88). The red point is the calculated shoreline position, and the red lines on either side of this point show the 95-percent confidence interval $(\mathrm{Cl})$ of the regression. This profile shows two foreshores, typical of a merging swash bar. By considering the length and height of the swash bar, the user should decide on which foreshore the shoreline should be located and delete solutions on the other foreshore. The user can also adjust the free parameters to try to get more solutions on the preferred foreshore.

resolution is $2.5 \mathrm{~m}$ and the alongshore resolution is $10 \mathrm{~m}$. In addition to a gridded topographic surface, this method produces a corresponding grid of the RMS error, which provides a measure of noise in the data. A Hanning filter with a width equal to two times the grid resolution was chosen in this study to minimize noise in the data associated with vegetation, alongshore variability, and other error sources while preserving distinct morphology. Analysis of cross-shore profiles of gridded data allows for automated extraction of dune crest and toe as well as shoreline position and beach slope at a regular alongshore interval.

The cross-shore location of the MHW shoreline is automatically extracted from gridded lidar data by using a probabilistic approach that makes use of the RMS error surface, providing for a statistically robust estimate (fig. 4). The probability that each gridded elevation was equal to the local MHW value is computed from a normal distribution of the beach elevation, using the interpolated elevation as the mean $(\mu)$ and the lidar scatter (noise) as the standard deviation $(\sigma)$. Using a prior shoreline as a first approximation, the grid cell with the highest probability within a defined distance (3 times the standard deviation of all shoreline points within the grid segment) of the prior shoreline is selected as the most likely shoreline. The defined distance is equal to 3 times the standard deviation of all shoreline points within the grid segment. Linear regression using the selected point and adjacent grid cells was used to identify a more precise crossshore location of the MHW line. The foreshore slope is the 


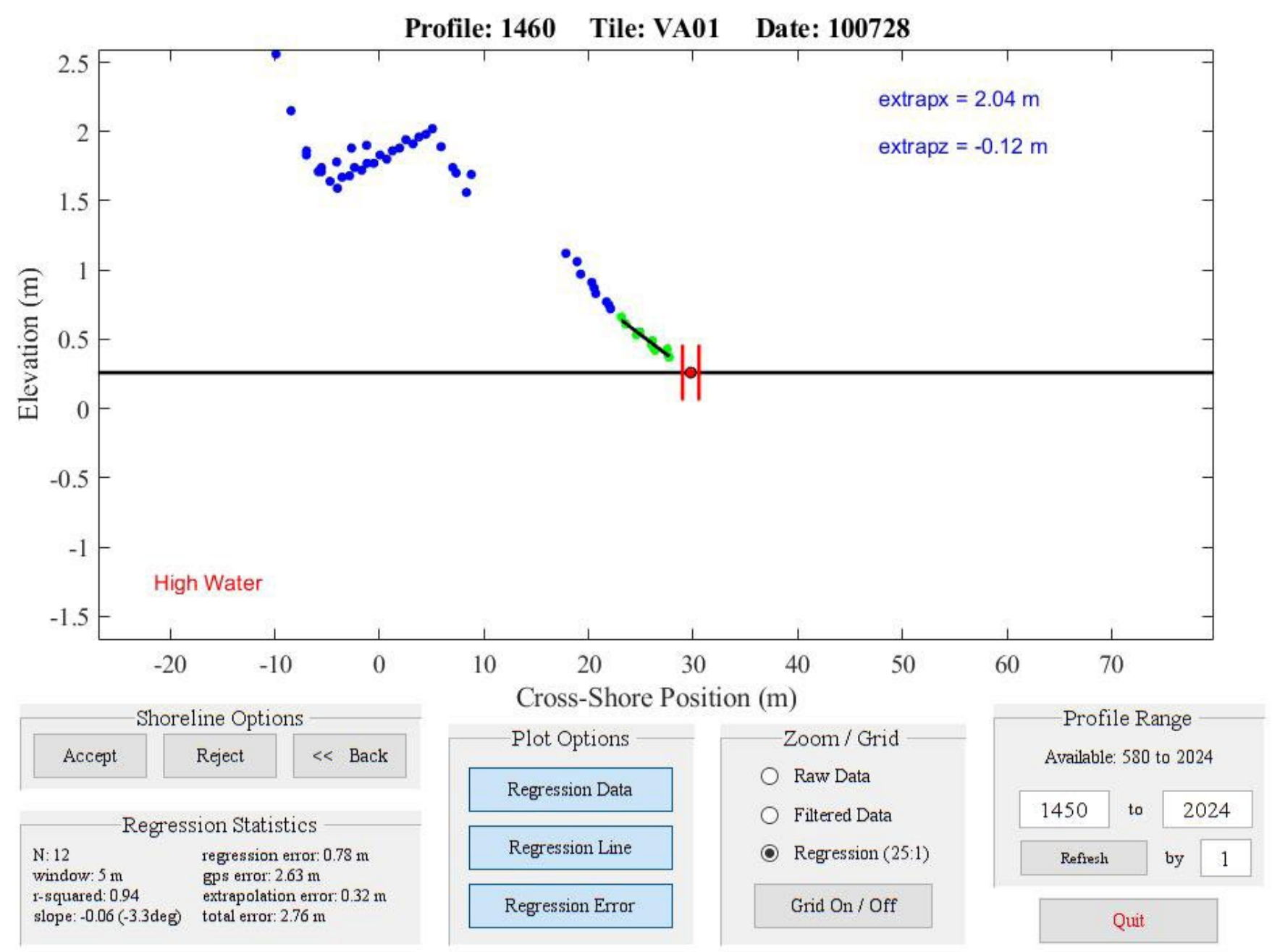

Figure 3. An example of an extrapolated solution. Blue points show cross-shore profile data. Green points are profile data used in the linear regression, with the slope of that linear regression shown by the thin black line through those points. Since there are no data at mean high water (MHW), the regression line is extrapolated to MHW (horizontal black line) yielding the calculated shoreline position (red point). The red lines of either side of this point show the 95-percent confidence interval (CI) of the regression. How far the extrapolation was done (both horizontally and vertically) is displayed in the upper right corner. $\mathrm{m}$, meter.

slope of the regression through these 3 points. As performed in the Profile method, a $15-\mathrm{cm}$ lidar drift error is assumed, and this slope is used to convert this drift to a horizontal error. To determine the 95 -percent CI for the gridded shoreline, a second regression is fit through the raw data points that were used in the creation of the smooth grid (20 m alongshore and $15 \mathrm{~m}$ cross-shore) and is evaluated at the MHW shoreline point determined from the grid. The 95-percent CI and lidar drift error are added in quadrature to get the total shoreline uncertainty.

A visual quality assurance/quality control (QA/QC) check of the shoreline is performed in $\operatorname{ArcGIS}^{\circledR}$ by overlaying the shoreline points on the gridded elevation data. Any spurious points (that is, shorelines that are too far landward or seaward) are deleted from the dataset.

\section{Contour Method}

This method is executed in $\operatorname{ArcGIS}^{\circledR}$. The raw lidar data (in .las file format) are loaded by using the function "LAS to multipoint" (ArcToolbox $>>3$ D Analyst Tools $>>$ Conversion $>>$ From File $>>$ LAS to Multipoint) with an average point spacing of $1 \mathrm{~m}$. A terrain is created, and the lidar data are imported into it (Arc Toolbox $>>$ 3DAnalyst Tools $>>$ Terrain Management $>>$ Add feature class to terrain). Next, a digital elevation model (DEM) is created by running "Terrain to raster" (ArcToolbox $>>3$ D Analyst Tools $>>$ Conversion >> From Terrain >> Terrain to Raster) by using the method "Natural Neighbors" and a cell size of $1 \mathrm{~m}$. The MHW elevation is contoured using "Contour" (ArcToolbox $>>3$ D Analyst Tools $>>$ Raster Surface $>>$ Contour ). The contour interval is set to be $50 \mathrm{~m}$ and the base contour to be $0.46 \mathrm{~m} \mathrm{MHW}$. 


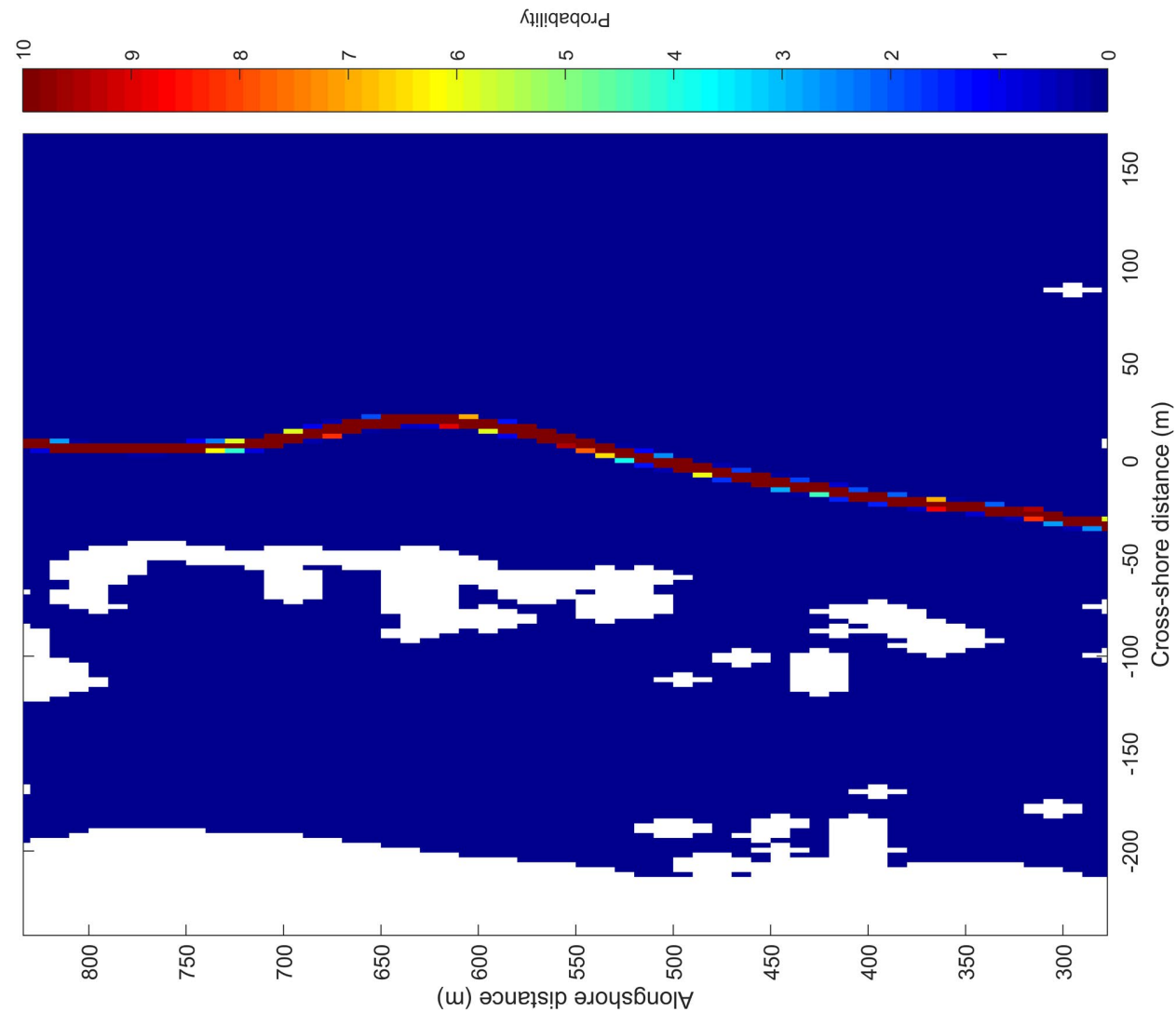

(w) บоำ
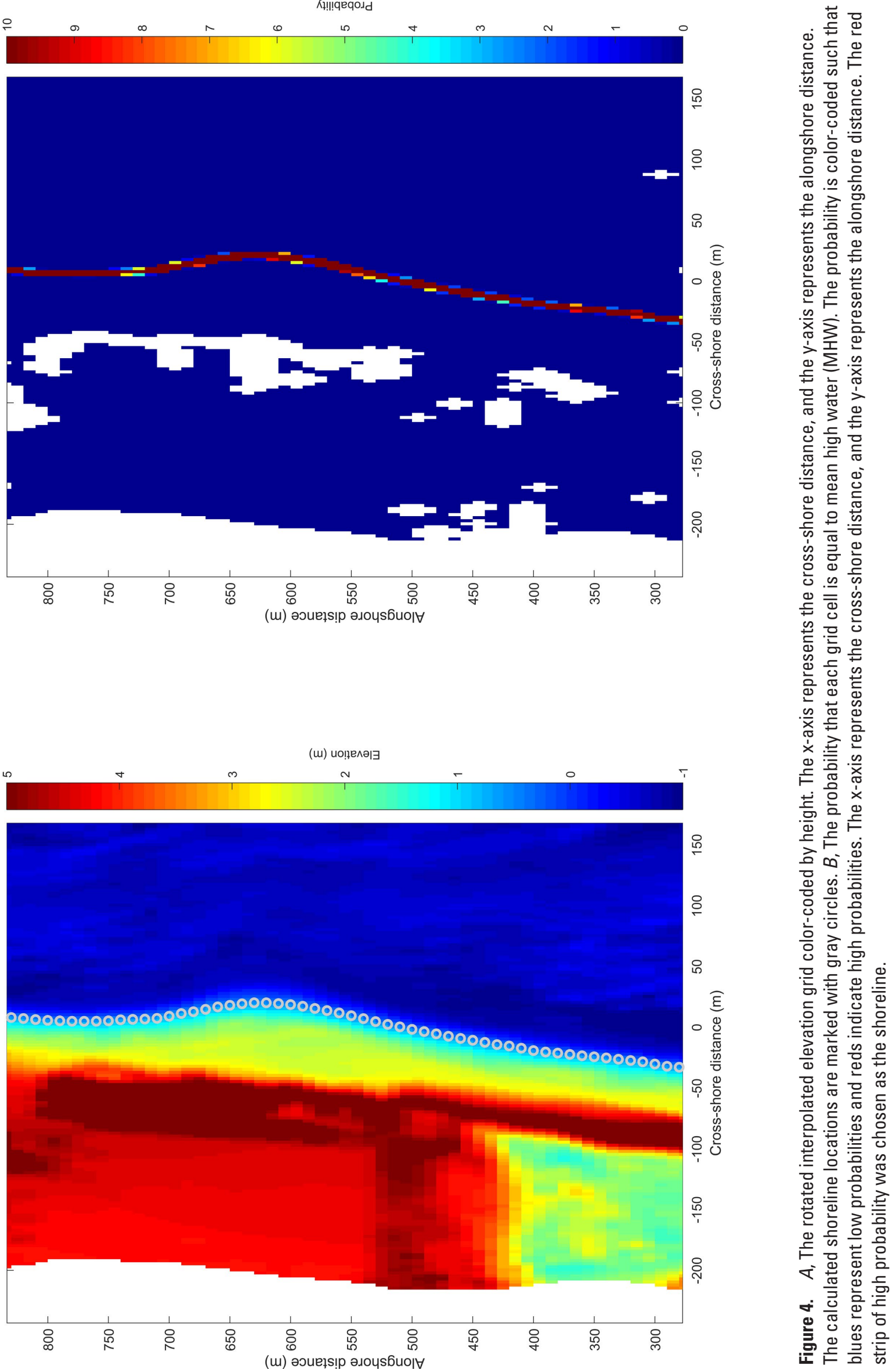
There are several ways to estimate the uncertainty associated with this methodology. At the time this shoreline was extracted, the uncertainty was estimated by considering two sources of error: Global Positioning System (GPS) position error, which was estimated to be $\pm 1 \mathrm{~m}$, and regression errors, which were estimated to be $\pm 1.5 \mathrm{~m}$ (Hapke et al, 2006). These two terms were added in quadrature to get a bulk estimate of an uncertainty of $1.8 \mathrm{~m}$.

\section{Smoothed Contour Method}

The $0.46-\mathrm{m}$ contour found by using the Contour method is smoothed by using ArcToolbox $>>$ Data Management Tools $>>$ Generalization $>>$ Simplify Line. The algorithm used is Bend Simplify. As explained later in the text, ArcTools $>>$ Cartography Tools $>>$ Generalization $>>$ Smooth Line, with PAEK smoothing algorithm set to $10 \mathrm{~m}$, was also used in another iteration.

\section{Smoothed Contour/Manual Hybrid Method}

The $0.46-\mathrm{m}$ contour found by using the Contour method is manually evaluated/edited by using the source lidar surface with categorized elevation values that highlight the exact MHW values and those that fall within $0.5 \mathrm{~m}$ of MHW. This provides guidance in the absence of MHW or where there are multiple MHW values. Additional 3D Analyst tools such as "Interpolate Line," which provides a cross section of the elevation data, are used to evaluate the position of MHW when there is ambiguity in MHW. After the contour is edited, it is smoothed using "Smooth Line."

\section{Comparison Methods}

In our main comparison of all methods, we used the September 30, 2000, survey and interpolated the shoreline from each method onto the 50-m, alongshore-spaced transects from the Coastal and Marine Geology Program's National Assessment of Coastal Change Hazards Long-Term Coastal Change task (Himmelstoss and others, 2010). Throughout the rest of this document, these transects are referred to as " $50-\mathrm{m}$ transects." Because these standard transects were used, no shoreline positions for any of the three methods were at their originally derived locations, and thus all were subject to the increase in error associated with interpolation. The comparison described here only evaluated differences in shoreline position between the methods, with no consideration of method uncertainty.

In the second test, also using the September 30, 2000, lidar survey, shoreline position uncertainty for the Grid and Profile methods was evaluated (table 1). These are the only methods that provide a point-by-point measure of uncertainty. For this test, data as originally derived at a $20-\mathrm{m}$ alongshore spacing with no interpolation were used.
In the third test, the November 5, 2012, lidar survey was used, and Grid, Profile, and Smoothed Contour/Manual Hybrid shorelines were compared for a section of coast with a complex morphology.

Finally, additional factors which might be considered when selecting a method were qualitatively evaluated.

\section{Results}

\section{Comparison of Shoreline Position Interpolated to 50-Meter Transects (September 30, 2000, Lidar Survey)}

After interpolating shorelines from all methods onto the 50-m transects, each shoreline was compared with all the others graphically and by finding the mean difference, RMS difference, and RMS difference after the mean difference is removed. An example of the graphical difference is given in figure 5. Summary statistics for all method comparisons are given in table 2 (mean differences), table 3 (RMS differences), and table 4 (RMS differences, after the mean difference is removed). The differences between methods, in terms of both mean and RMS difference, were very small. Most of the mean differences were less than $0.1 \mathrm{~m}$ (table 2), and the RMS differences (table 3) were all less than $1.0 \mathrm{~m}$. The RMS differences after the mean differences were removed were not significantly different than the RMS differences.

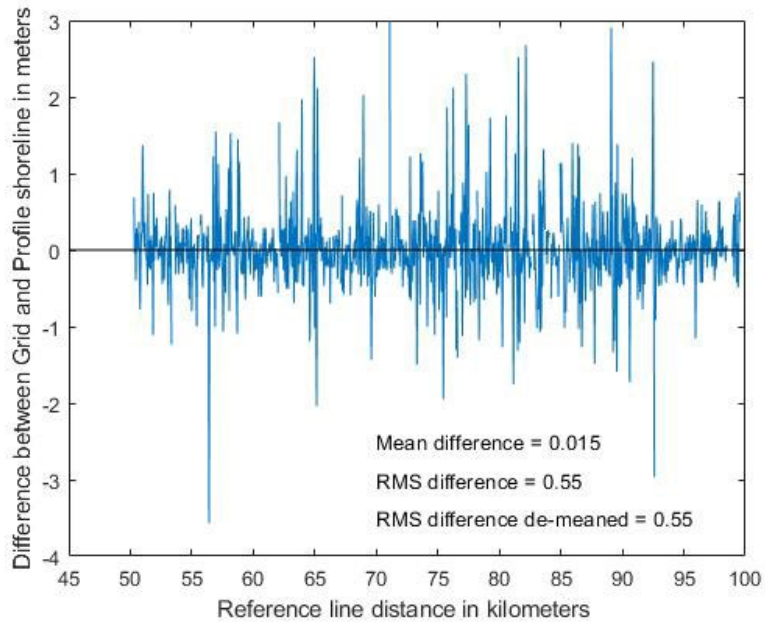

Figure 5. An example of the spatial variability of differences between shoreline methods. This plot shows the difference between the Grid and Profile methods for the September 30, 2000, survey. The $\mathrm{x}$-axis represents distance along the coast. Both shorelines were interpolated onto 50-meter transects before being subtracted. Positive values indicate that Grid shoreline is seaward of Profile shoreline. RMS, root mean square. 
Table 2. Mean differences in shoreline positions (in meters).

[Shorelines were derived from different methods using the September 30, 2000, survey and interpolated onto 50-meter (m) transects. Positive numbers indicate that the average shoreline position derived from the Column Method was shifted seaward of the shoreline position derived from the Row Method (for example, Grid is landward of Profile 20 by $0.17 \mathrm{~m}$ ). Profile 10 used 10-m maximum cross-shore window width; Profile 20 used a 20-m maximum cross-shore window width. --, none]

\begin{tabular}{lccccc}
\hline \multicolumn{1}{c}{ Method } & Grid & Profile20 & Profile10 & Contour & $\begin{array}{c}\text { Smoothed Contour } \\
\text { Bend Simplify }\end{array}$ \\
\hline Grid & -- & -- & - & -- & -- \\
Profile20 & -0.17 & -- & - & - & - \\
Profile10 & 0.02 & 0.18 & -- & - & - \\
Contour & 0.06 & 0.22 & 0.03 & -- & - \\
Smoothed Contour Bend Simplify & 0.09 & 0.26 & 0.06 & 0.03 & - \\
Smoothed Contour Smooth Line & 0.06 & 0.22 & 0.04 & 0.00 & -0.03 \\
\hline
\end{tabular}

Table 3. Root mean square (RMS) differences in shoreline positions (in meters).

[Shorelines were derived from different methods using the September 30, 2000, survey and interpolated onto 50-meter (m) transects. Profile 10 used 10-m maximum cross-shore window width; Profile 20 used a 20-m maximum cross-shore window width. --, none]

\begin{tabular}{lccccc}
\hline \multicolumn{1}{c}{ Method } & Grid & Profile20 & Profile10 & Contour & $\begin{array}{c}\text { Smoothed Contour } \\
\text { Bend Simplify }\end{array}$ \\
\hline Grid & -- & -- & -- & -- & -- \\
Profile20 & 0.54 & -- & -- & -- & -- \\
Profile10 & 0.55 & 0.48 & -- & -- & - \\
Contour & 0.64 & 0.87 & 0.88 & -- & -- \\
Smoothed Contour Bend Simplify & 0.67 & 0.91 & 0.89 & 0.62 & -- \\
Smoothed Contour Smooth Line & 0.47 & 0.75 & 0.77 & 0.34 & 0.48 \\
\hline
\end{tabular}

Table 4. Root mean square (RMS) differences in shoreline positions after the mean difference is removed.

[Shorelines were derived from different methods using the September 30, 2000, survey and interpolated onto 50-meter (m) transects. Profile10 used 10-m maximum cross-shore window width; Profile20 used a 20-m maximum cross-shore window width. --, none]

\begin{tabular}{lccccc}
\hline \multicolumn{1}{c}{ Method } & Grid & Profile20 & Profile10 & Contour & $\begin{array}{c}\text { Smoothed Contour } \\
\text { Bend Simplify }\end{array}$ \\
\hline Grid & -- & -- & -- & -- & -- \\
Profile20 & 0.51 & -- & -- & -- & -- \\
Profile10 & 0.55 & 0.45 & -- & -- & -- \\
Contour & 0.64 & 0.84 & 0.88 & -- & -- \\
Smoothed Contour Bend Simplify & 0.66 & 0.88 & 0.89 & 0.62 & 0.48 \\
Smoothed Contour Smooth Line & 0.47 & 0.72 & 0.77 & 0.34 & \\
\hline
\end{tabular}


The differences between the methods seen in tables 2-4 are smaller than expected from natural shoreline position variability. Thus, all three shoreline extraction methods give an equivalent result.

\section{Evaluation of Uncertainty for Grid and Profile Methods at Originally Derived 20-Meter Transect Spacing (September 30, 2000, Survey)}

The Grid and Profile (10-m window) methods were compared at originally derived locations, that is, without interpolation onto new transect locations as in our comparison between all the methods. The mean and RMS differences between these two measures (fig. 6) is almost identical to the difference after interpolation onto the 50-m transects (fig. 5).

The Profile method uncertainty terms (95-percent CI, lidar drift error, and total error) were plotted versus the Profile method's foreshore slope (fig. 7). Uncertainty decreased with increasing beach slope for all terms. The 95-percent CI term represented the uncertainty in the linear fit to the lidar foreshore points selected by the program. The lidar drift error was calculated as drift/slope, where drift was the assumed unresolved potential vertical bias of the entire lidar point cloud. We used a vertical drift of $\pm 0.15 \mathrm{~m}$ based on Sallenger and others (2003). The total error was the quadrature sum of the 95-percent CI and lidar drift errors. Because the 95-percent CI was the smaller of the two terms, it added scatter to the uncertainty floor given by the lidar drift error.

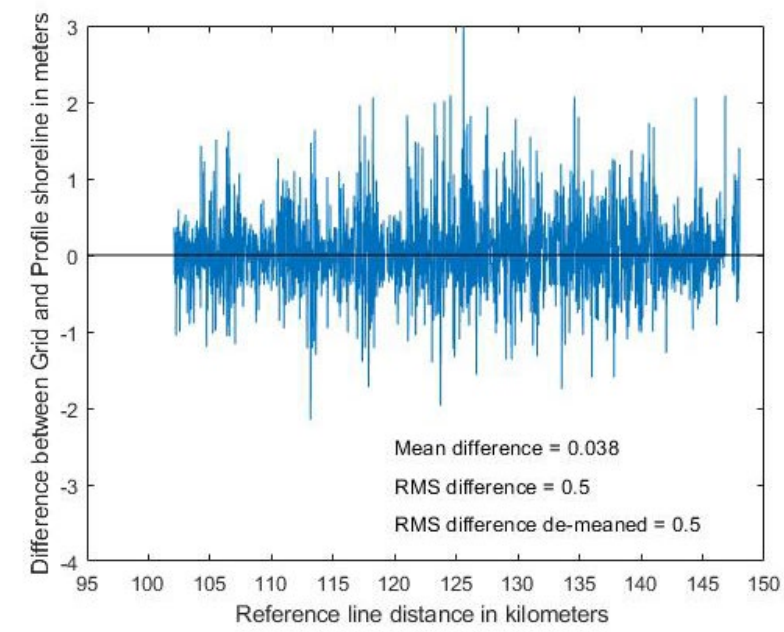

Figure 6. The spatial variability of differences between Grid shoreline and Profile shoreline when they are still at their originally derived locations (as opposed to interpolated onto the 50-meter $(\mathrm{m})$ transects). The $\mathrm{x}$-axis represents distance along the coast. Both shorelines are derived from the September 30, 2000 , lidar survey. (Positive values indicate that Grid shoreline is seaward of Profile shoreline.) RMS, root mean square.

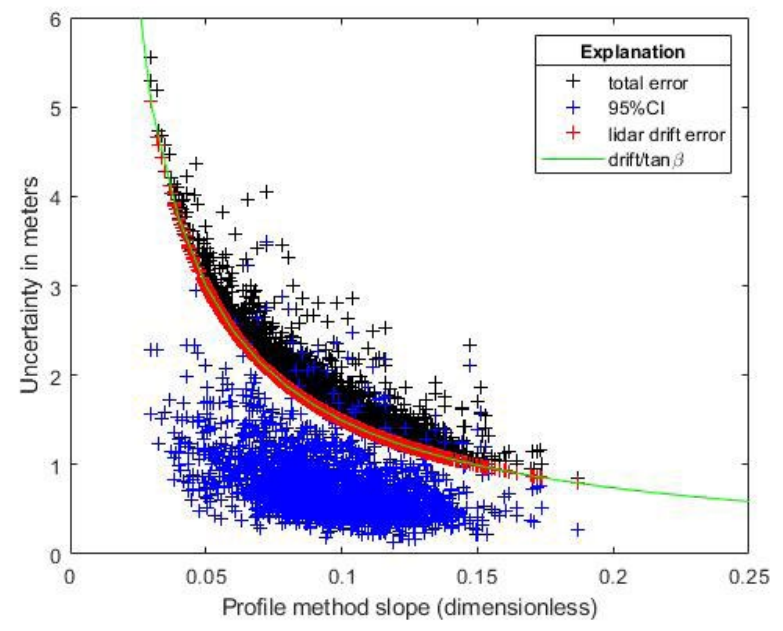

Figure 7. Profile method uncertainty terms versus Profile method foreshore slope, for the September 30, 2000, survey. The beach slope is expressed as $\Delta y / \Delta x$. The Profile shoreline was derived by using the 10-meter maximum cross-shore window width. The blue crosses are the 95-percent confidence interval (CI) of the linear regression for each transect. The red crosses are the lidar drift error for each transect. The green line is the drift error $(0.15$ meter [m]) divided by the tangent of the beach slope. The black crosses are the total error for each transect.

A similar effect was observed in Grid method uncertainty (fig. 8). Grid uncertainty was calculated from two terms. The first source of uncertainty was the 95-percent CI for the gridded shoreline, which was calculated by fitting a second regression through the raw data points that were used in the creation of the smooth grid. The other source of uncertainty was the lidar drift error. The 95-percent CI and lidar drift error were added in quadrature to calculate total shoreline uncertainty.

\section{Discussion}

\section{Comparison of Shoreline Position Interpolated to 50-Meter Transects (September 30, 2000, Lidar Survey)}

In table 2, the "Profile20" method refers to the Profile method using a maximum cross-shore window width of $20 \mathrm{~m}$ for the linear regression. Relative to all the other methods, the Profile20 shoreline was shifted seaward between 0.17 and $0.27 \mathrm{~m}$, whereas all the other mean differences in table 2 are $0.1 \mathrm{~m}$ or less. Lowering the maximum regression window for the Profile method to 10 m removed this bias ("Profile10," 


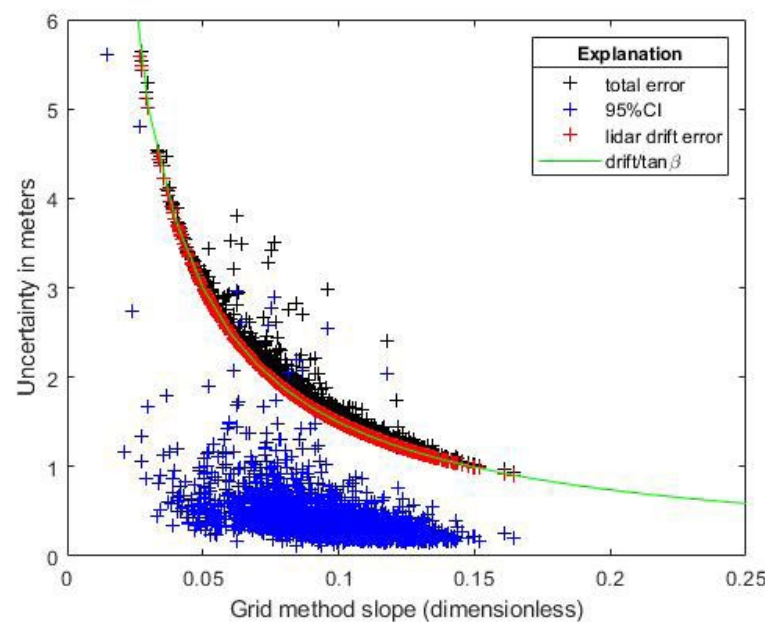

Figure 8. Grid method uncertainty terms versus Grid method foreshore slope, for the September 30, 2000, survey. The beach slope is expressed as $\Delta y / \Delta x$. The blue crosses are the 95 -percent confidence interval $(\mathrm{CI})$ of the linear regression for each transect. The red crosses are the lidar drift error for each transect. The green line is the drift error ( 0.15 meter $[\mathrm{m}])$ divided by the tangent of the beach slope. The black crosses are the total error for each transect.

table 2), suggesting that a 20-m window was picking up some water points, lowering the slope of the regression, and pushing the shoreline slightly seaward. In response to this issue, a new automatic procedure was developed to prevent this problem in the future by doing an initial quick and automated check of the sensitivity of mean shoreline position to the window width, which will prevent this problem in the future. Nevertheless, a shift in shoreline position of $0.2 \mathrm{~m}$ is not significant in studies of shoreline change. All plots of Profile data in this work use the $10-\mathrm{m}$ maximum window size.

In table 4, the RMS difference increased slightly from the "Contour" to the "Smoothed Contour, Bend Simplify" method. This was unexpected because the Contour method was based on an ArcGIS $\AA$ triangulated irregular network (TIN) grid with no smoothing, so it had been expected that the RMS difference, relative to the other methods, would be reduced when the contour was smoothed. A map-view examination of what ArcToolbox Bend Simplify provides (fig. 9) shows that it only retains a decimated set of original points and typically follows the position noise envelope (bouncing back and forth to either side of the envelope). The ArcToolbox "Smooth Line" smoother, on the other hand, creates a more reasonable smoothed version of the Contour shoreline (fig. 9), and the RMS difference relative to other methods (table 4) shows a corresponding decrease as expected. Use of "Smooth Line" rather than "Simplify Line" is therefore recommended.

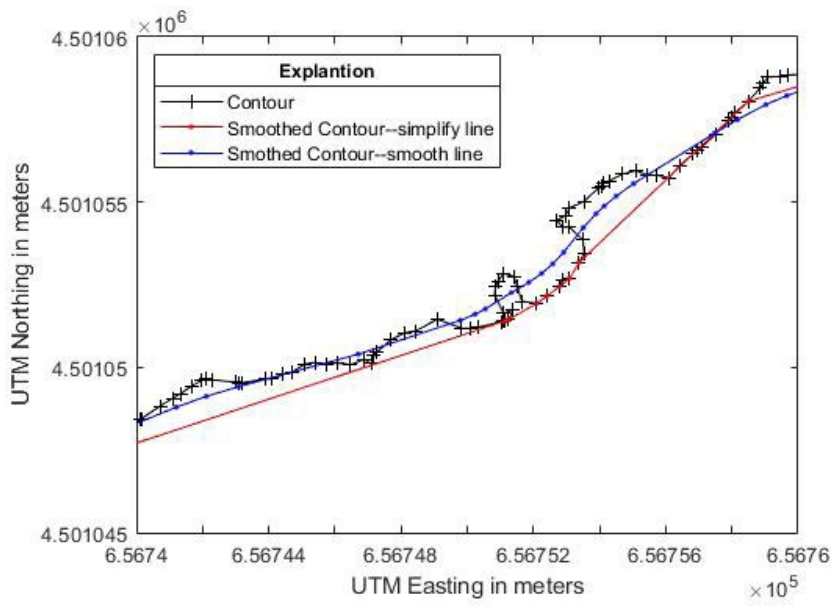

Figure 9. Map view comparison of variations of the Contour shoreline method using the September 30, 2000, lidar survey. The black line (with black crosses at shoreline points) is the contoured shoreline. The red line (with red dots at shoreline points) is the result when the contoured shoreline was smoothed using "Simplify Line" in ArcToolbox. The blue line (with blue dots at shoreline points) is the result when the contoured shoreline is smoothed using "Smooth Line." UTM, Universal Transverse Mercator.

\section{Uncertainty}

In addition to shoreline position, the Grid and Profile methods provide an estimate of point-by-point position uncertainty. This level of detail in uncertainty rather than a bulk estimate is required for several applications, including estimating the uncertainty shoreline change using the end point method (generally only useful in tightly controlled prestorm and poststorm comparisons), finding the uncertainty of a regionally averaged change (or rate) when using the endpoint method (needed for determining the number of independent samples), and the Kalman filter method of forecasting shoreline change. When the shoreline change rate is found through a simple linear regression through three or more shorelines, a point-by-point estimate of shoreline position uncertainty is not necessary.

\section{Effect of Complex Morphology}

An example of the potential challenge of complex morphology is demonstrated in figure 10, which compares shorelines derived by the Grid, Profile, and Smoothed Contour/ Manual Hybrid methods using the November 5, 2012, lidar survey. This survey was done about a week after Hurricane Sandy, when sand that had been eroded from the beach during the storm was returning to the beach. Thus, there was complex 


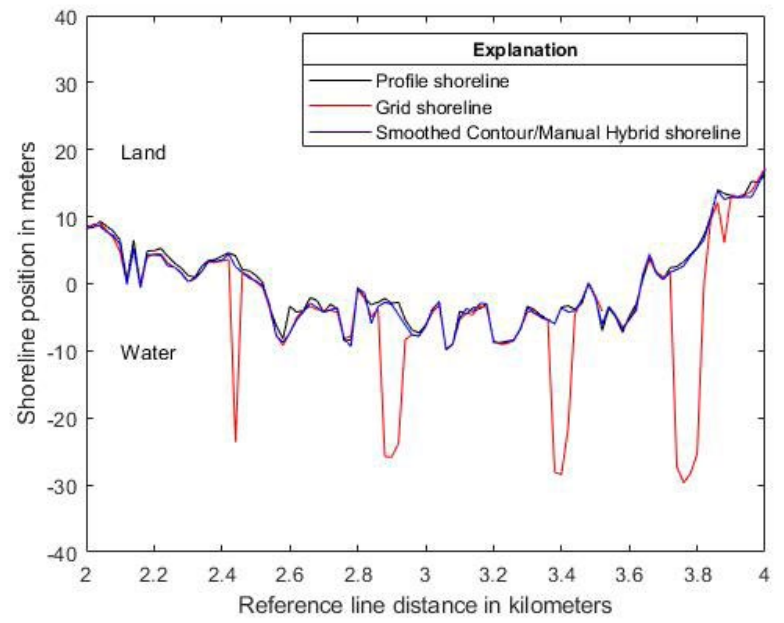

Figure 10. A comparison between Grid, Profile, and Smoothed Contour/Manual hybrid methods for deriving shorelines using data collected on November 5, 2012. The Smoothed Contour/ Manual Hybrid shoreline was derived according to the Contour method, then manually edited and smoothed by using the Smooth Line method. Shoreline position is relative to a reference line, and the shorelines were rotated to facilitate exaggeration of the differences. The $x$-axis represents distance along the coast.

morphology consisting of multiple partially welded swash bars (for an example of a partially welded swash bar, see fig. 2). This morphology resulted in the Grid method shoreline having multiple 20-30-m jumps to a more seaward position. While these are likely valid intersections of the MHW datum with the topography, it may not be desirable to include these ephemeral features into a shoreline intended to be part of a larger database suitable for calculating long-term change. Figure 10 shows the section of coast with the largest differences between shorelines derived by the Grid method and other methods. The magnitude of differences between these shorelines was not representative of the entire study area; differences were much less for the remaining coastline.

\section{Additional Qualitative Factors}

In addition to the evaluations given above, a number of additional factors could influence the choice of method for deriving shorelines from lidar data, including efficiency, quality control, portability to other users, and the ability to handle lidar data collected when water levels are high and MHW is partially obscured.

When lidar data are clean (for example, lacking multiple elevation envelopes from multiple passes, water level is low enough that MHW is fully subaerial, there is no complex beach morphology such as multiple berms, and so on) the Profile method can be run quickly and without visually checking the results (as is typically done for each profile when using this method). The Fire Island lidar data survey selected for this comparison is a very clean dataset with no complicating issues. However, when the lidar data are less than perfect, a detailed profile-by-profile visual inspection is required to identify problems and maintain product quality. As it is currently constructed, the Grid method is time efficient but only allows for a rough, visual map-view assessment of the shoreline quality. While the method may be consistently rapid, which is necessary for certain applications where immediate results are required (storm response, for example), incorporation of Grid method shorelines into a long-term database of shoreline positions may be problematic unless more thorough $\mathrm{QA} / \mathrm{QC}$ is done.

Portability to other users, both within the USGS Coastal and Marine Geology Program and external, is a desirable trait of any method. Only the ArcGIS ${ }^{\circledR}$-based Contour method, along with its two smoothing variations, meets a reasonable standard of portability. Both the Profile and Grid methods require an in-house code and method expert with the ability to frequently adjust parameters and rewrite code to accommodate new problems. Neither of these methods could be easily transferred to external users or easily documented in their entirety. Work is planned to make the USGS shoreline methods user friendly and externally available in the future.

Table 5 summarizes the qualities a user could consider when choosing a methodology for the extraction of a shoreline from lidar data. 
Table 5. Comparison of methods.

[MHW, mean high water; lidar, light detection and ranging; m, meter]

\begin{tabular}{|c|c|c|}
\hline Method & Pros & Cons \\
\hline Profile & $\begin{array}{l}\text { - Provides a shoreline with high quality control, suitable for } \\
\text { incorporation into permanent long-term databases of shore- } \\
\text { line position. } \\
\text { - Permits the extrapolation of linear regression to the MHW } \\
\text { elevation in cases of lidar data collected during high water, } \\
\text { including the addition of an uncertainty term due to extrapo- } \\
\text { lation. } \\
\text { - Includes methodology for handling complex beach morpholo- } \\
\text { gies, such as multiple berms with multiple MHW positions. } \\
\text { - Provides point-by-point uncertainty. }\end{array}$ & $\begin{array}{l}\text { - May be more time consuming than the Grid method. } \\
\text { - Only uses lidar data in a user-specified alongshore window } \\
\text { surrounding the profile location (typically } 2 \mathrm{~m} \text { ). } \\
\text { - Requires expert knowledge of code, which is not easily por- } \\
\text { table to other users. }\end{array}$ \\
\hline Grid & $\begin{array}{l}\text { - May be faster than the Profile method. } \\
\text { - Uses more of the lidar data than the Profile method. } \\
\text { - Differential alongshore versus cross-shore smoothing creates } \\
\text { a more smoothed version of the shoreline, which is under } \\
\text { user control. } \\
\text { - Provides point-by-point uncertainty. }\end{array}$ & $\begin{array}{l}\text { - Only has a rudimentary ability to identify and handle com- } \\
\text { plex beach morphology, such as multiple berms containing } \\
\text { multiple positions of MHW. } \\
\text { - Cannot handle lidar datasets in which the water level is high } \\
\text { and partially obscures MHW (that is, cannot extrapolate the } \\
\text { linear regression downslope to the MHW elevation). } \\
\text { - Requires expert knowledge of code, which is not easily por- } \\
\text { table to other users. }\end{array}$ \\
\hline Contour & $\begin{array}{l}\text { - Highly portable to other users, both internal and external, that } \\
\text { are familiar with ArcGIS } \\
\text { - A similar method could be used with many other software } \\
\text { packages capable of gridding elevation data and exporting } \\
\text { an elevation contour. However, an equivalent to ArcTool- } \\
\text { box's "Smooth Line" routine may not be widely available. } \\
\text { - Efficiency of shoreline extraction. }\end{array}$ & $\begin{array}{l}\text { - Cannot handle lidar datasets in which the water level is high } \\
\text { and partially obscures MHW (that is, cannot extrapolate the } \\
\text { linear regression downslope to the MHW elevation). } \\
\text { - Cannot handle complex beach morphology, such as multiple } \\
\text { berms containing multiple positions of MHW, without some } \\
\text { manual editing. } \\
\text { - Provides only a rough bulk estimate of uncertainty. }\end{array}$ \\
\hline
\end{tabular}

\section{Conclusions}

Results from three methods for deriving mean high water (MHW) shorelines from light detection and ranging (lidar) surveys were compared, and strengths and weaknesses of each method were enumerated. The overall conclusion of this comparison is that, for a high-quality coastal topographic lidar survey, such the September 30, 2000, survey used here, there is very little difference in the shoreline position between methods. For certain applications, such as finding a shoreline change rate through a simple linear regression, it makes little difference which method is used.

One difference in the methods is in the assessment of shoreline position uncertainty. Several applications using shoreline position data require an estimate of uncertainty that varies profile by profile. These include finding the uncertainty of regionally averaged rates and the Kalman filter method of projecting shoreline change rates. The Profile and Grid methods provide a point-by-point estimate of uncertainty, whereas the Contour method provides only a bulk estimate of uncertainty.

A further difference in the methods, only discussed qualitatively here, exists in cases when the lidar data are not high quality (for example, multiple elevation envelopes from multiple flight passes), when the water level is higher than optimal (near or above MHW) during the lidar survey, or when the beach has a complex morphology that includes multiple berm crests and MHW positions. In these cases, detailed and often time-consuming quality-control procedures developed for the Profile method are necessary to ensure a shoreline suitable for incorporation into long-term databases of shoreline position. These shorelines are typically shared with the public and will be used in ways that cannot be anticipated, and therefore they need to be of the best possible quality.

\section{Acknowledgments}

We thank the USGS personnel who that assisted in this comparison in many ways, from calculating the shoreline position using the various methods, to helping us understand the methods. In particular, Rachel Henderson is thanked for several iterations of the Contour and Manual shorelines and Emily Himmelstoss is thanked for her suggestion to use the ArcToolbox smooth line routine. 


\section{References Cited}

Hapke, C.J., Reid, D., Richmond, B.M., Ruggiero, P., and List, J., 2006, National assessment of shoreline change-Part 3: Historical shoreline changes and associated coastal land loss along the sandy shorelines of the California coast: U.S. Geological Survey Open-File Report 2006-1219. [Also available at https://pubs.er.usgs.gov/publication/ ofr20061219.]

Himmelstoss, E.A., Kratzmann, M.G., Hapke, C., Thieler, E.R., and List, J.H., 2010, The national assessment of shoreline change-A GIS compilation of vector shorelines and associated shoreline change data for the New England and Mid-Atlantic Coasts: U.S. Geological Survey Open-File Report 2010-1119, accessed September 2012 at https://pubs.er.usgs.gov/publication/ofr20101119.

National Oceanic and Atmospheric Administration [NOAA], 2000, 2000 fall east coast NOAA/USGS/NASA Airborne LiDAR Assessment of Coastal Erosion (ALACE) project for the US coastline: National Oceanic and Atmospheric Administration dataset, accessed September 2012 at https://coast.noaa.gov/htdata/lidar1_z/geoid12a/data/11/.

Plant, N.G., Holland, K.T., and Puleo, J.A., 2002, Analysis of the scale of errors in nearshore bathymetric data: Marine Geology, v. 191, no. 1-2, p. 71-86 [Also available at https://doi.org/10.1016/S0025-3227(02)00497-8.]
Sallenger, A.H., Jr., Krabill, W.B., Swift, R.N., Brock, J.C., List, J., Hansen, M.E., Holman, R.A., Manizade, S., Sontag, J., Meredith, A., Morgan, K.L.M., Yunkel, J.K., Frederick, E.B., and Stockdon, H.F., 2003, Evaluation of airborne scanning lidar for coastal change applications - 1. Beach topography \& changes: Journal of Coastal Research, v. 19, p. 125-133.

Stockdon, H.F., Sallenger, A.H., Jr., List, J.H., and Holman, R.A., 2002, Estimation of shoreline position and change using airborne topographic lidar data: Journal of Coastal Research, v. 18, p. 502-513.

U.S. Geological Survey [USGS], 2012, 2012 U.S. Geological Survey topographic lidar- Northeast Atlantic coast postHurricane Sandy: U.S. Geological Survey dataset, accessed October 2015 at https://coast.noaa.gov/htdata/lidar1_z/ geoid12a/data/2488/.

Weber, K.M., List, J.H., and Morgan, L.M.M., 2005, An operational mean high water datum for determination of shoreline position from topographic lidar data: U.S. Geological Survey Open-File Report 2005-1027, 100 p., accessed October 2012 at https://pubs.usgs.gov/of/2005/1027/. 

For more information about this report, contact:

Director, Woods Hole Coastal and Marine Science Center

U.S. Geological Survey

384 Woods Hole Road

Quissett Campus

Woods Hole, MA 02543-1598

WHSC_science_director@usgs.gov

(508) 548-8700 or (508) 457-2200

or visit our website at

https://woodshole.er.usgs.gov

Publishing support provided by the

Pembroke Publishing Service Center 


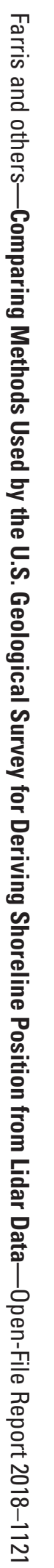

